\title{
Computational Fluid Dynamics Modeling Three-Dimensional Unsteady Turbulent Flow and Excitation Force in Partial Admission Air Turbine
}

\author{
Yonghui Xie, ${ }^{1}$ Keke Gao, ${ }^{1}$ Jibing Lan, ${ }^{1}$ and Gongnan Xie ${ }^{2}$ \\ ${ }^{1}$ School of Energy and Power Engineering, Xian Jiaotong University, Xian, Shaanxi 710049, China \\ ${ }^{2}$ Engineering Simulation and Aerospace Computing (ESAC), School of Mechanical Engineering, Northwestern Polytechnical University, \\ P.O. Box 552, Xian, Shaanxi 710072, China
}

Correspondence should be addressed to Yonghui Xie; yhxie@mail.xjtu.edu.cn

Received 11 October 2013; Accepted 11 November 2013

Academic Editor: Shaoyong Lai

Copyright (c) 2013 Yonghui Xie et al. This is an open access article distributed under the Creative Commons Attribution License, which permits unrestricted use, distribution, and reproduction in any medium, provided the original work is properly cited.

\begin{abstract}
Air turbines are widely used to convert kinetic energy into power output in power engineering. The unsteady performance of air turbines with partial admission not only influences the aerodynamic performance and thermodynamic efficiency of turbine but also generates strong excitation force on blades to impair the turbine safely operating. Based on three-dimensional viscous compressible Navier-stokes equations, the present study employs RNG (Renormalization group) $k$ - $\varepsilon$ turbulence model with finite volume discretization on air turbine with partial admission. Numerical models of four different admission rates with full annulus are built and analyzed via CFD (computational fluid dynamics) modeling unsteady flows. Results indicate that the unsteady timeaveraged isentropic efficiency is lower than the steady isentropic efficiency, and this difference rises as unsteady isentropic efficiency fluctuates stronger when the admission rate is reduced. The rotor axial and tangential forces with time are provided for all four admission rates. The low frequency excitation forces generated by partial admission are extraordinarily higher than the high frequency excitation forces by stator wakes.
\end{abstract}

\section{Introduction}

Partial admission is one of steam distribution modes in the control stage of turbine to admit fluid only into part of circumferential segmental arcs of the inlet annulus. Flow in a partial admission turbine is extremely more complex than that in full admission. Partial admission is widely used to regulate power output and reduce the tip leakage and secondary flow losses. But the parameters of partial admission in the circumferential direction are extremely nonuniform compared with full admission, and then excitation force is enhanced greatly. Vibration fatigue fracture is the common form of turbine blade failure. Because of the complexity of flow field, the essence of problem cannot be revealed by traditional methods. Only in the late 20th century, with the increasing capacity of computers, the problem is gradually indepth study. Using numerical investigation of unsteady flow of partial admission to get the real aerodynamic blade force changing with time is one of the effective ways to study the blade vibration.

The main investigations of partial admission date from the late 1960s and early 1970s. In 1970s, experimental investigation has been performed to enhance the understanding of turbine clearance influence with different admission of superheated and wet steam by Pryakhin and Pavlovskii [1]. Test on two-stage turbine was performed using a variable control method. When the effect of radial clearance of the first row of rotor is tested, keep the radial and axial clearance of second row constant. Finally it was concluded that the effect of clearance on efficiency and degree of reaction was independent. In 1990s, Wakeley and Potts [2] presented the analysis of unsteady characteristics in partial admission, and the effect of alternating stress and partial admission on efficiency were also discussed. He [3] investigated the 
influence of unsteady flow on aerodynamic performance using a multirow, multipassage Navier-Stokes solver. The results have shown that unsteady loads and mixing losses can be caused by circumferential suction phenomenon of rotor. Two-stage turbine results suggested that the attenuation of circumferential nonuniform has strongly relation with aerodynamic performance. At the beginning of 21st century, study on partial admission flow in $200 \mathrm{MW}$ steam turbine control stage was performed by Lampart et al. [4]. 2D midspan Navier-Stokes flow model is assumed since $3 \mathrm{D}$ Navier-Stokes computations need more huge resources. The unsteady force of single rotor and unsteady load of all rotors are computed. The results of numerical simulation of full annulus of the partial admission agreed with the experimental research well performed by Sakai et al. [5]. The impact of circumferential position of inlet on efficiency was discussed. It was concluded that there was optimal inlet position that makes efficiency highest. Cho et al. [6] presented the effect of flow parameter on aerodynamic performance of partial admission axial flow turbine, such as nozzle flow outlet angle, solidity of rotor. The optimal parameters were obtained using three different solidities and four nozzle flow outlet angle in experiment. Numerical analysis of aerodynamic performance of the multistage axial flow turbine was presented by Li et al. [7] using three-dimensional unsteady Navier-Stokes equation based on Baldwin-Lomax model. A cascade experiment was conducted by Cho et al. [8], who investigate the effect of partial admission on turbine performance. The experiment is shown the maximum rotational force increased but the maximum axial force decreased at Reynolds number of $3 \times 10^{5}$ based on chord when solidity was decreased. Both experimental and numerical analyses were conducted by Hushmandi et al. [9] on two-stage axial turbine of low degree of reaction. The circumferential amplitude of unsteady force of first row of rotor was demonstrated using fast fourier transform algorithm. The results shown the excitation force amplitude was even bigger at integral multiple of rotor rotation frequency. Lampart et al. [10] presented detailed flow distribution and unsteady force of rotor by means of numerical simulation of two kinds of control stage in partial admission. A method was proposed to decrease unsteady force by improving nozzle of control stage. The full and partial admission flows were investigated by Newton et al. [11]. The conclusion is shown that the main entropy increase of full admission existed at blade tip, while it existed at outlet of nozzle, inlet of rotor for partial admission. And flow losses distribution was obvious through entropy increase analysis. Forced response in partial admission axial turbines were presented by Fridh et al. [12]. An extended design criteria toolbox and validation data, for control-stage design based on experimental data in partial-admission turbines were presented.

Three-dimensional full annulus model was adopted at four different admissions in this paper. Detailed numerical analysis of unsteady flow at different admission in air turbine was conducted by using CFD (computational fluid dynamics) technique. Three-dimensional viscous compressible turbulent flow was simulated with the RNG (Re-normalization group) $k-\varepsilon$ turbulence model. Four different admission rates

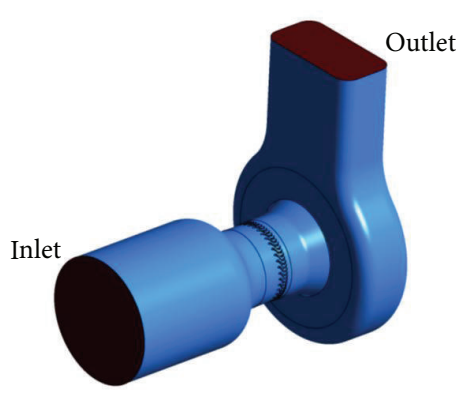

FIGURE 1: Three-dimensional model of the air turbine.

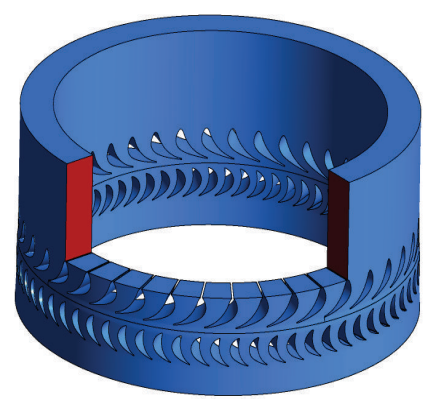

Figure 2: $\xi=0.75$ Cascade passage.

TABLE 1: Geometric parameters.

\begin{tabular}{lc}
\hline Geometric parameters & Value \\
\hline Nozzle numbers & 40 \\
Nozzle height/mm & 33.4 \\
Rotor numbers & 65 \\
Rotor height/mm & 34.4 \\
\hline
\end{tabular}

with Isentropic efficiency, rotational force, and axial force changed with time in different admissions were investigated in details.

\section{Computational Analysis Method}

2.1. Computational Model. This paper presents a partial admission air turbine with different admission and particular exhaust passage. The full annulus model is required for the cyclical asymmetry resulted from overall structure. The turbine blade parameters are shown in Table 1. Air turbine investigated is composed of intake passage, nozzle, rotor, and exhaust passage. Four admissions, $\xi$, are considered, that is, $0.25,0.5,0.75$, and 1.0. The geometric model is shown in Figures 1 and 2. All parts of grid are shown in Figures 3, 4, and 5. Thermal parameters are shown in Table 2.

Block-structured grid is adopted in order to conform to the requirements of complex structure and topological relations of intake passage, cascade passage and exhaust passage. The computational grid consisted only of hexahedral grid, which the near wall is $\mathrm{O}$ type meshed and the far wall is $\mathrm{H}$ type grid. 


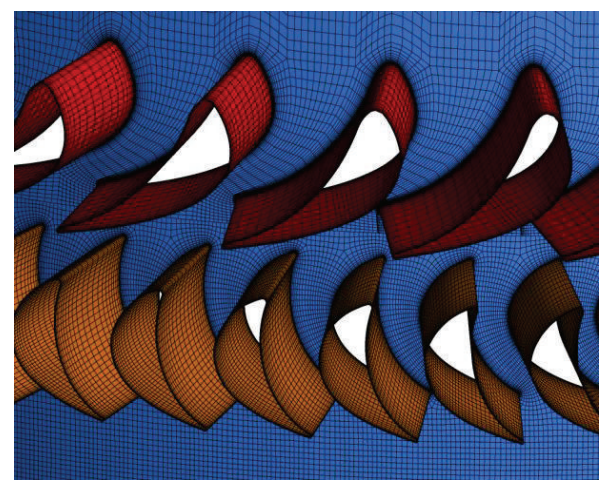

FIgURE 3: Cascade passage.

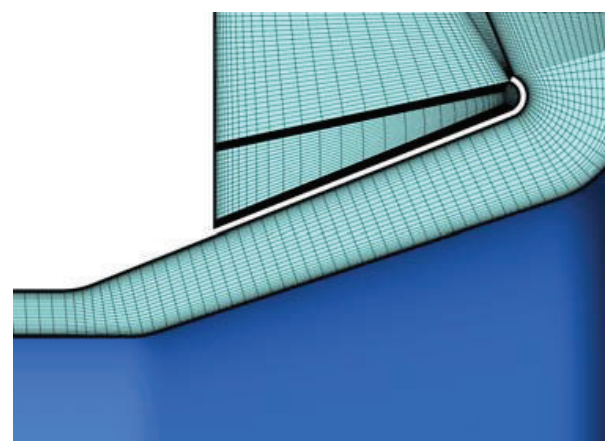

Figure 4: Exhaust passage.

TABLE 2: Thermal parameters of turbine stage.

\begin{tabular}{lcc}
\hline Parameters & Unit & Value \\
\hline Inlet total pressure & $\mathrm{kPa}$ & 130 \\
Inlet total temperature & $\mathrm{K}$ & 323.05 \\
Outlet static pressure & $\mathrm{kPa}$ & 97 \\
Revolving speed & $\mathrm{rpm}$ & 5000 \\
\hline
\end{tabular}

Considering the computational precise and time, the grid independence verification is needed for single channel cascade. Four types of grids are analyzed at full admission. The relative deviation of isentropic efficiency between the adjacent grid decreases when the node of grid increases. The grid applied meets relative deviation within $0.2 \%$. The grid independence verification is shown in Table 3 . In addition, the local distributions of static pressure of nozzle and rotor at $50 \%$ blade height of four grid system are also given as Figures 6 and 7. As shown in the results, the grid 3 applied coincide well with grid 4 . The whole circle model grids are, respectively, 65000000, 63000000, 60000000, and 58000000 nodes at four types of admissions.

2.2. Computational Method and Boundary Condition. Reynolds time-averaged Navier-stokes equations are solved by commercial CFD software of ANSYS-CFX. The Cartesian

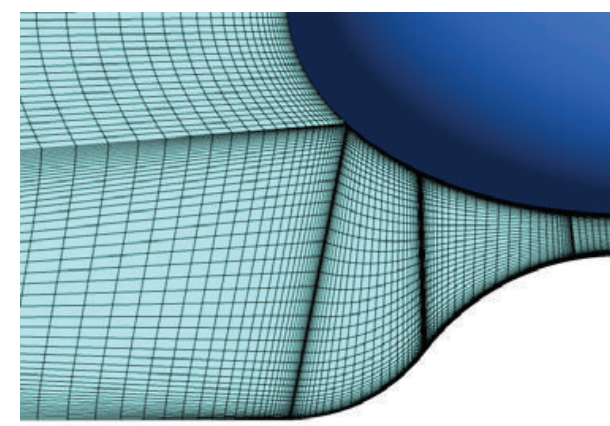

FIGURE 5: Intake passage.

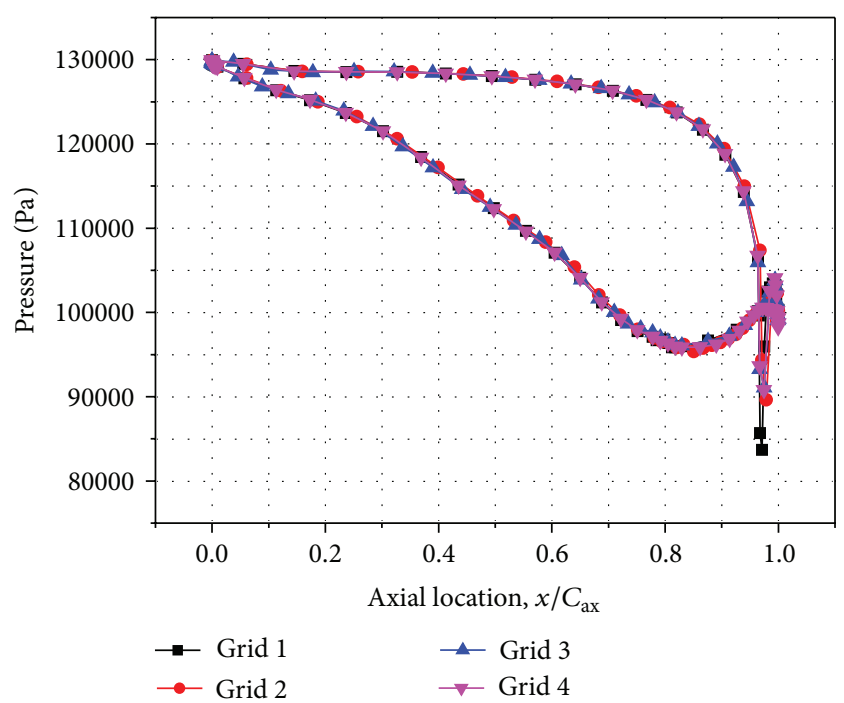

FIgURE 6: Static pressure distribution of nozzle at $50 \%$ blade height.

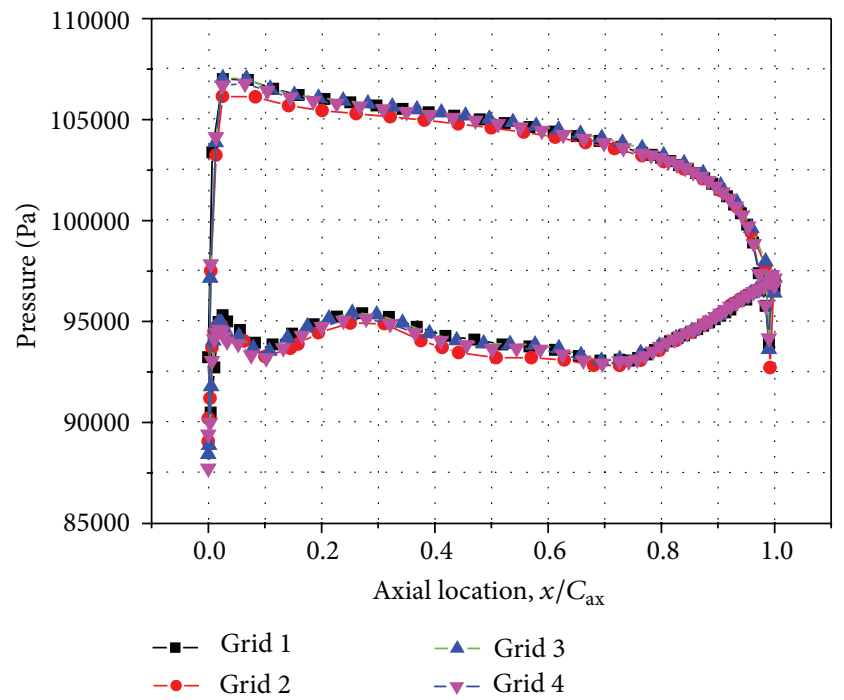

FIGURE 7: Static pressure distribution of rotor at 50\% blade height. 
TABLE 3: Grid-independent validation.

\begin{tabular}{lccc}
\hline Nozzle grid nodes & Rotor grid nodes & Isentropic efficiency/\% & Deviation/\% \\
\hline 33870 & 30070 & 81.93 & 0.99 \\
40060 & 36015 & 82.75 & 0.48 \\
48800 & 43300 & 83.15 & 0.20 \\
58570 & 51950 & 83.32 & - \\
\hline
\end{tabular}

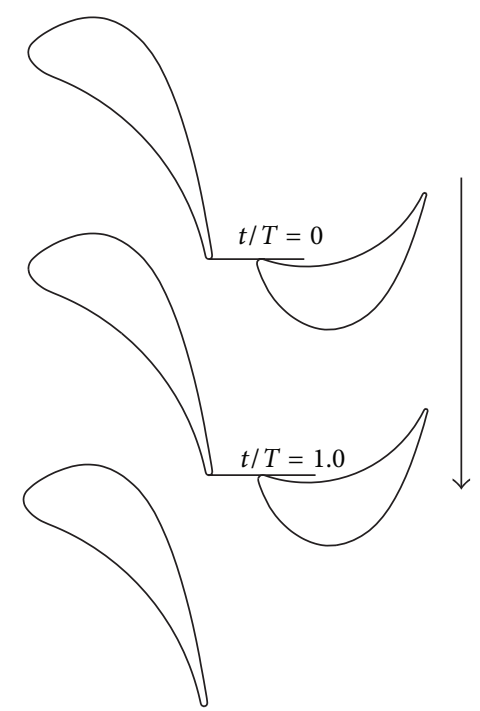

FIGURE 8: Relative position of stator and rotor with one period.

coordinates for three-dimensional viscous unsteady flow control equation is as follows:

$$
\frac{\partial(\rho \phi)}{\partial t}+\operatorname{div}(\rho \vec{U} \phi)=\operatorname{div}\left(\Gamma_{\phi} \operatorname{grad} \phi\right)+S_{\phi}
$$

where $\phi$ is universal variable for the different equations, $\Gamma_{\phi}$ is generalized diffusion coefficient, and $S_{\phi}$ is generalize source term. Mass conservation equation, momentum conservation equation, and energy conservation equation can be obtained by setting $\phi$ to $1, u, v, w, t, k$, and $\varepsilon$.

RNG $k$ - $\varepsilon$ turbulence model improved by Yakhot and Orszag [13], which expand the unsteady Navier-Stokes equation via GAUSS statistics, is adopted in this paper, as employed by Hushmandi et al. [9] and Hajilouy-Benisi et al. [14]. And the effects of small-scale vortices are eliminated by spectrum analysis. The $\varepsilon$ term is added to nonlinear addition term expressed as $R_{\varepsilon}$ in RNG $k-\varepsilon$ turbulence model which is different from standard $k-\varepsilon$ equation. Simulation accuracy of rotational flow and big curvature flow condition is improved for the additional $R_{\varepsilon}$ The transport equations for RNG $k-\varepsilon$ turbulence model are given as follows.

For turbulent kinetic energy $k$ :

$$
\frac{\partial(\rho k)}{\partial t}+\frac{\partial\left(\rho k u_{i}\right)}{\partial x_{i}}=\frac{\partial}{\partial x_{j}}\left[\left(\mu+\frac{\mu_{t}}{\sigma_{k}}\right) \frac{\partial k}{\partial x_{j}}\right]+P_{k}-\rho \varepsilon
$$

For dissipation $\varepsilon$ :

$$
\begin{aligned}
& \frac{\partial(\rho \varepsilon)}{\partial t}+\frac{\partial\left(\rho \varepsilon u_{i}\right)}{\partial x_{i}} \\
& =\frac{\partial}{\partial x_{j}}\left[\left(\mu+\frac{\mu_{t}}{\sigma_{\varepsilon}}\right) \frac{\partial k}{\partial x_{j}}\right]+C_{1 \varepsilon} \frac{\varepsilon}{k} P_{k}-C_{2 \varepsilon} \frac{\varepsilon^{2}}{k} \rho-R_{\varepsilon}
\end{aligned}
$$

where

$$
R_{\varepsilon}=\frac{C_{\mu} \rho \eta^{3}\left(1-\eta / \eta_{0}\right)}{1+\beta \eta^{3}} \frac{\varepsilon^{2}}{k} .
$$

The governing equation is dispersed with finite volume method (FVM). Diffusion term and source term is dispersed with second-order cell-centered method. The high accuracy discretization schemes suggested by Barth and Jesperson [15] are applied for convective term. Dual time step implicit iteration method put forward by Jamson [16] is used for time term discretized. The total pressure and total temperature are set as inlet boundary, and the 5 percentage is available for turbulence intensity. The time step is equal to $0.00001 \mathrm{~s}$, which means that 1200 steps are required to cover one revolutions of the rotor for the revolving speed is $5000 \mathrm{r} / \mathrm{min}$. The sliding interface method is applied for rotor and nozzle blade interface problem. The combination of sliding interface between rotor and nozzle is updated as time goes on. The steady results are used for the unsteady computational initial condition to accelerate convergence for all cases. The axial force and tangential force of rotor are regarded as convergence parameters. That the turbine unsteady computation comes to convergence is ensured when the force is periodical change with time and the deviation is less than $1.0 \%$ between the monitor values of adjacent period.

\section{Computational Results and Analysis}

The computational results of full annulus time-average unsteady isentropic efficiency and steady efficiency at different admission during the time rotor pass through single nozzle passage are shown in Table 4 . It is found that the timeaverage unsteady isentropic efficiency is lower than steady isentropic efficiency, respectively, 5.18\%, 4.66\%, 1.55\%, and $1.04 \%$ at admission equal to $0.25,0.5,0.75$, and 1.0 . The mixing losses increase because of fierce unsteady effect at partial admission. The flow characteristics of turbine are described more accuracy by means of unsteady computation. And the difference between time-average unsteady efficiency and steady efficiency becomes smaller with admission increasing.

A single nozzle pitch passing period expressed as $T$ is given in Figure 8. The leading edge of rotor just under the 


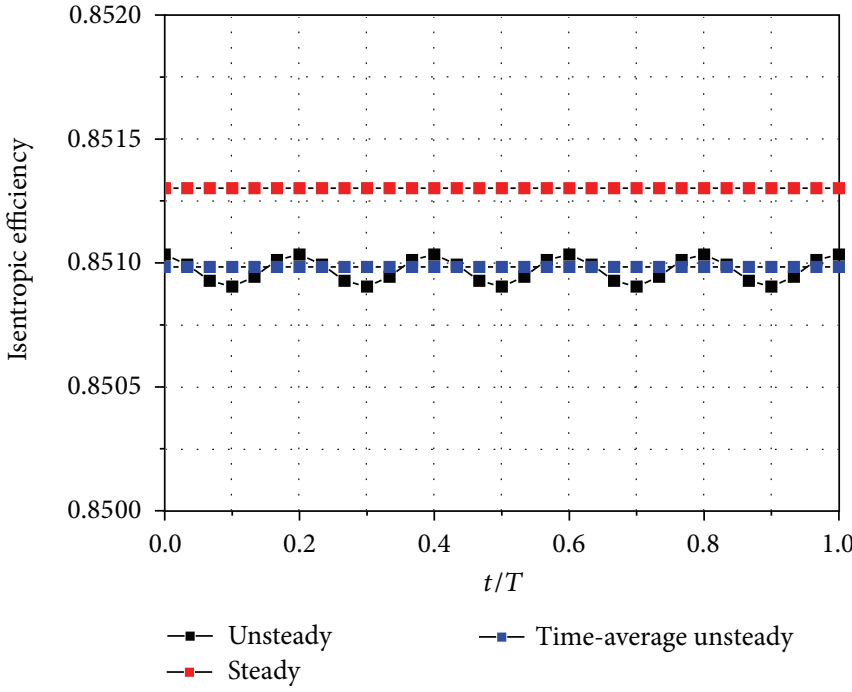

(a) Admission $\xi=1.0$

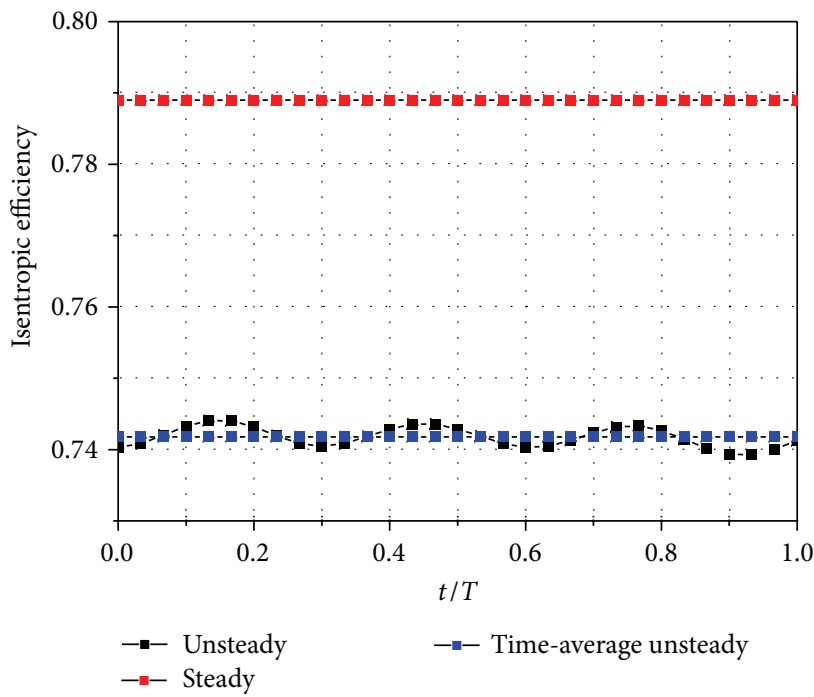

(c) Admission $\xi=0.5$

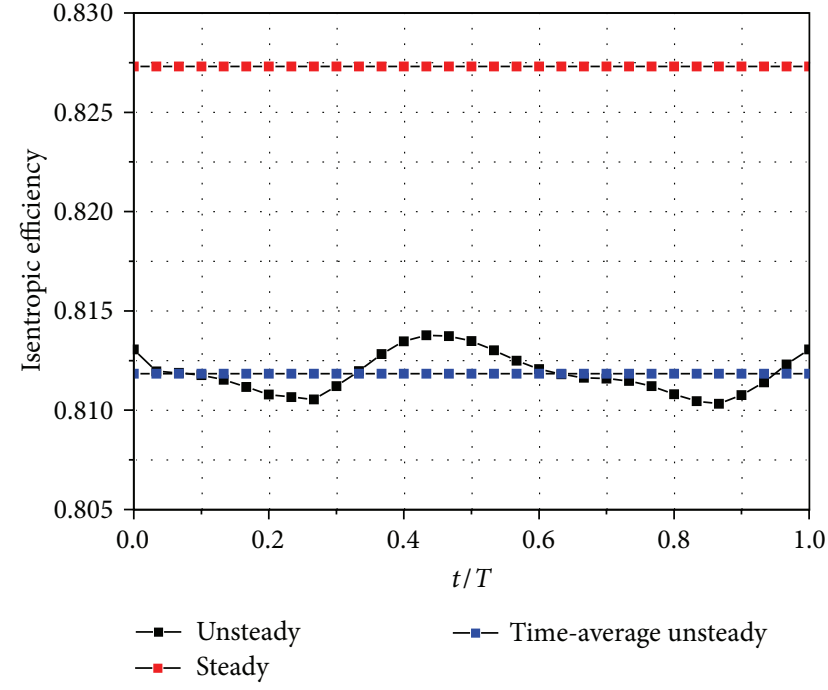

(b) Admission $\xi=0.75$

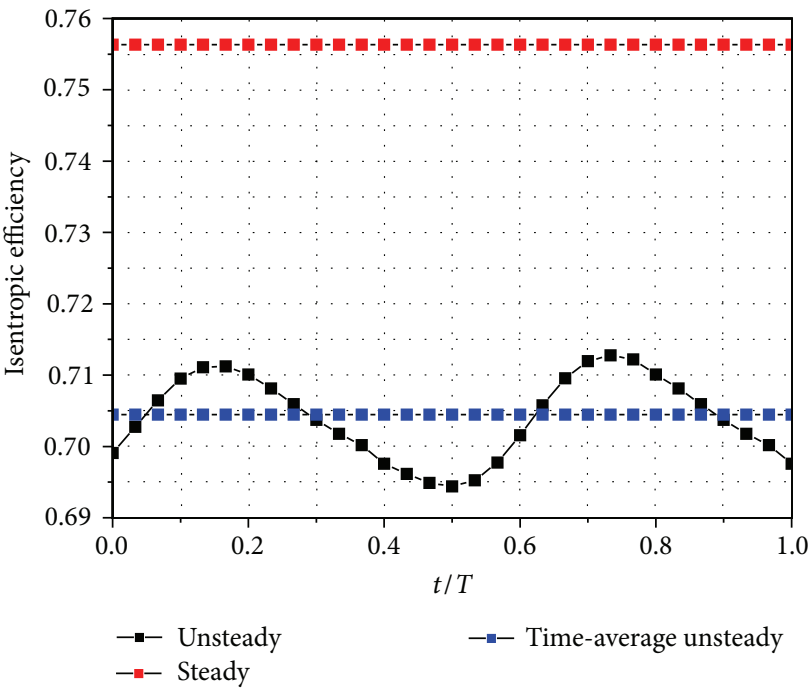

(d) Admission $\xi=0.25$

FIGURE 9: Isentropic efficiency changes with time.

TABLE 4: Isentropic efficiency of turbine.

\begin{tabular}{lccc}
\hline Admission & Time-average unsteady isentropic efficiency/\% & Unsteady isentropic efficiency/\% & Offset/\% \\
\hline 0.25 & 70.45 & 75.63 & 5.18 \\
0.5 & 74.18 & 78.90 & 4.66 \\
0.75 & 81.18 & 82.73 & 1.55 \\
1.0 & 84.09 & 85.13 & 1.04 \\
\hline
\end{tabular}

nozzle trailing edge at $t / T=0$, and the leading edge of rotor exactly moves to the trailing edge of next nozzle at $t / T=1.0$.

The unsteady isentropic efficiency, time-average unsteady efficiency and steady efficiency varied with time in a single nozzle pitch passing period are shown in Figure 9. The flow field instability increases when the admission decreases, and then the fluctuation of unsteady isentropic efficiency become greater. The unsteady flow characteristics become more obvious. The difference value of unsteady instantaneous isentropic efficiency between maximum and minimum is 1.834 percentages at partial admission of 0.25 . But the difference between unsteady instantaneous isentropic efficiency peak value is only 0.013 percentage at partial admission of 1.0. And the differences of isentropic efficiency peak value are 0.477 percentages, 0.346 percentages, respectively, for partial admission of 0.5 and 0.75 . 


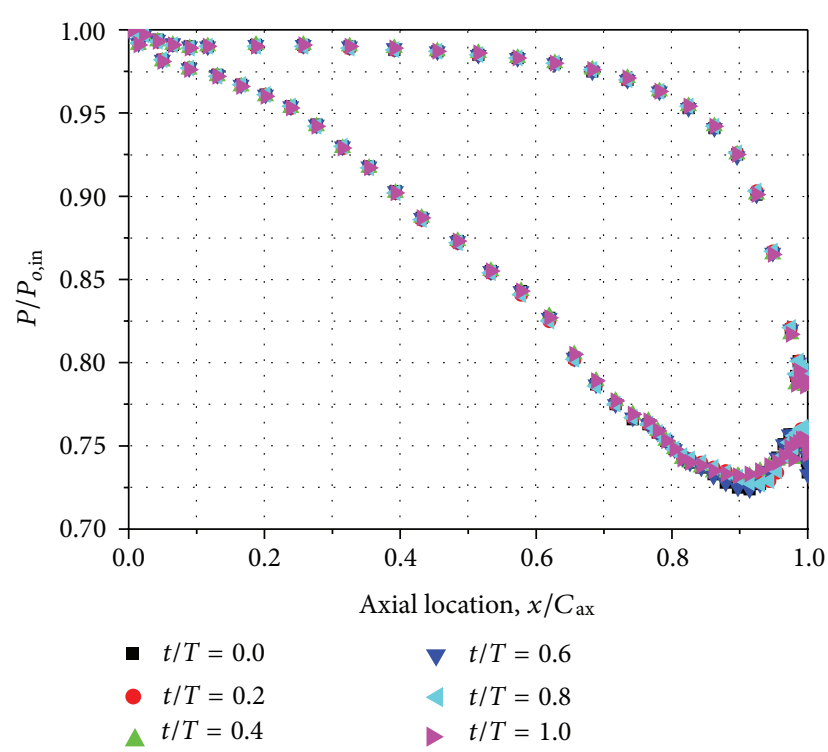

FIGURE 10: Static pressure distribution of nozzle at $50 \%$ blade height.

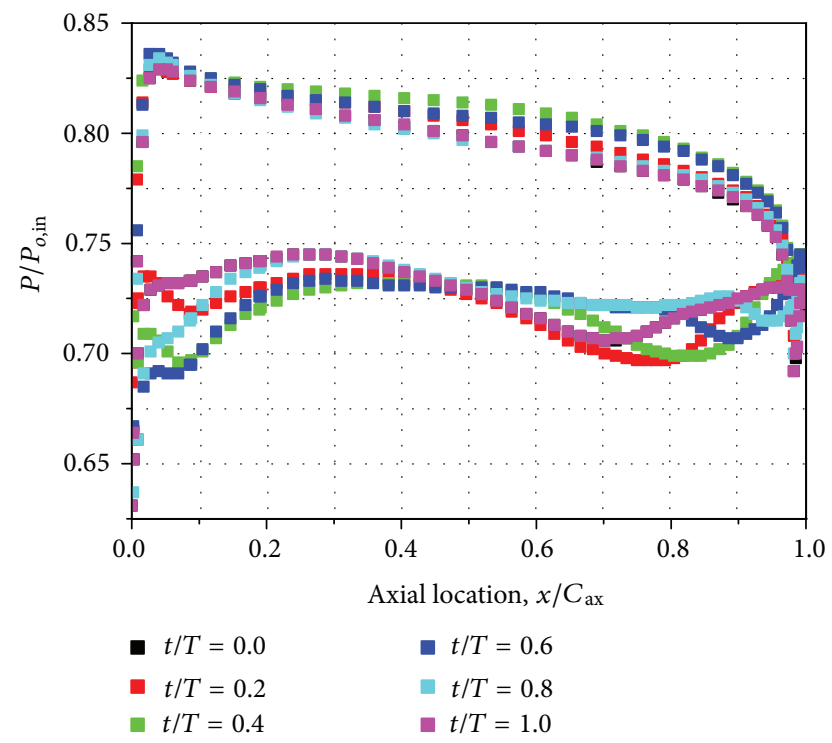

FIGURE 11: Static pressure distribution of rotor at $50 \%$ blade height.

A better insight into the output power of blade can be obtained by investigating the blade surface pressure, and the aerodynamic efficiency is also influenced by blade surface pressure to some extent. The blade surface pressure changes are caused by flow field varied with time on unsteady condition.

Static pressure distribution varied with time of nozzle at $50 \%$ blade height is shown in Figure 10 when the admission is 1.0. Nondimensional number $P / P_{\mathrm{o}, \text { in }}$, where the $P$ is static pressure and $P_{\mathrm{o} \text {,in }}$ is total pressure of inlet. It is shown that the static pressure amplitude of variation is small with time in Figure 10. The static pressure distribution is almost overlapping in the leading edge of nozzle, while pressure pulse exists in the trailing edge of nozzle. The pressure pulse is mainly caused by rotor-stator interactions.

Static pressure distribution varied with time of rotor at $50 \%$ blade height is shown in Figure 11 when the admission is 1.0. It is presented that the area between rotor pressure surface and suction surface is different varied with time steps in Figure 11. The aerodynamic force suffered by rotor is different with time, and the isentropic efficiency fluctuates as well. The rotor pressure surface and suction surface all exists certain fluctuations, but the suction surface pressure is relative large. Rotor is affected obviously by nozzle wake.

The internal flow process and blade pressure change are similar for all kinds of partial admission. The case of partial admission of 0.75 is chosen to analyze the typical surface pressure distribution of rotor and nozzle.

The typical blade location is shown in Figure 12 when $t / T$ is equal to 0 . S1 stands for nozzle of inlet section, R1 for the rotor of blocked section, R2 for the rotor of inlet section, $\mathrm{R} 3$ for the transition section rotor at entrance to the blocked section, and R4 for the transition section rotor at entrance to the inlet section.

The static pressure distribution of 50 percentage blade height in one period is presented in Figure 13 for S1 of inlet section. The static pressure amplitude of variation is small as time goes on except for the pressure pulse in the trailing edge of nozzle. The static pressure distribution of 50 percentage blade height in one period is presented in Figure 14 for R1 of inlet section. It is presented that the area between rotor pressure surface and suction surface is different varied with time steps in Figure 14. And then, the rotor suffered from unsteady aerodynamic force, the power generated is also different. It is found out from the static pressure distribution of R1, $\mathrm{S} 1$ at $50 \%$ blade height that the pressure of inlet section blades are not influenced much due to the partial admission. And the power capability of inlet section is also not changed much in partial admission.

The static pressure distribution of 50 percentage blade height in one period is presented in Figure 15 for R2 rotor of blocked section. The static pressure distribution of $\mathrm{R} 2$ rotor is gradually steady with time changing. The differential pressure between pressure surface and suction surface is small for the stationary flow in the channel in this period. And the pressure changes at the axial direction are also small because the internal channel is full of stagnant fluid and extremely low vortex is the main flow.

The static pressure distribution of 50 percentage blade height in one period is presented in Figure 16 for R3 rotor of transition section at the entrance to inlet section. It is found that the static pressure of $\mathrm{R} 3$ rotor is quite strong at the entrance to inlet section in a single pitch passing period. The pressure surface and suction surface of leading edge changes firstly caused by incoming flow as rotor is approaching to inlet section. The pressure surface pressure shoots up, while suction pressure experience two processes. It is clearly found that suction pressure rises gradually from $t / T=0.0$ to $t / T=0.4$. The main reason for the pressure rises is that suction surface enters into inlet section first and is affected by incoming flow. When $t / T$ is equal to 0.6 , suction pressure declines gradually and pressure surface pressure continue 


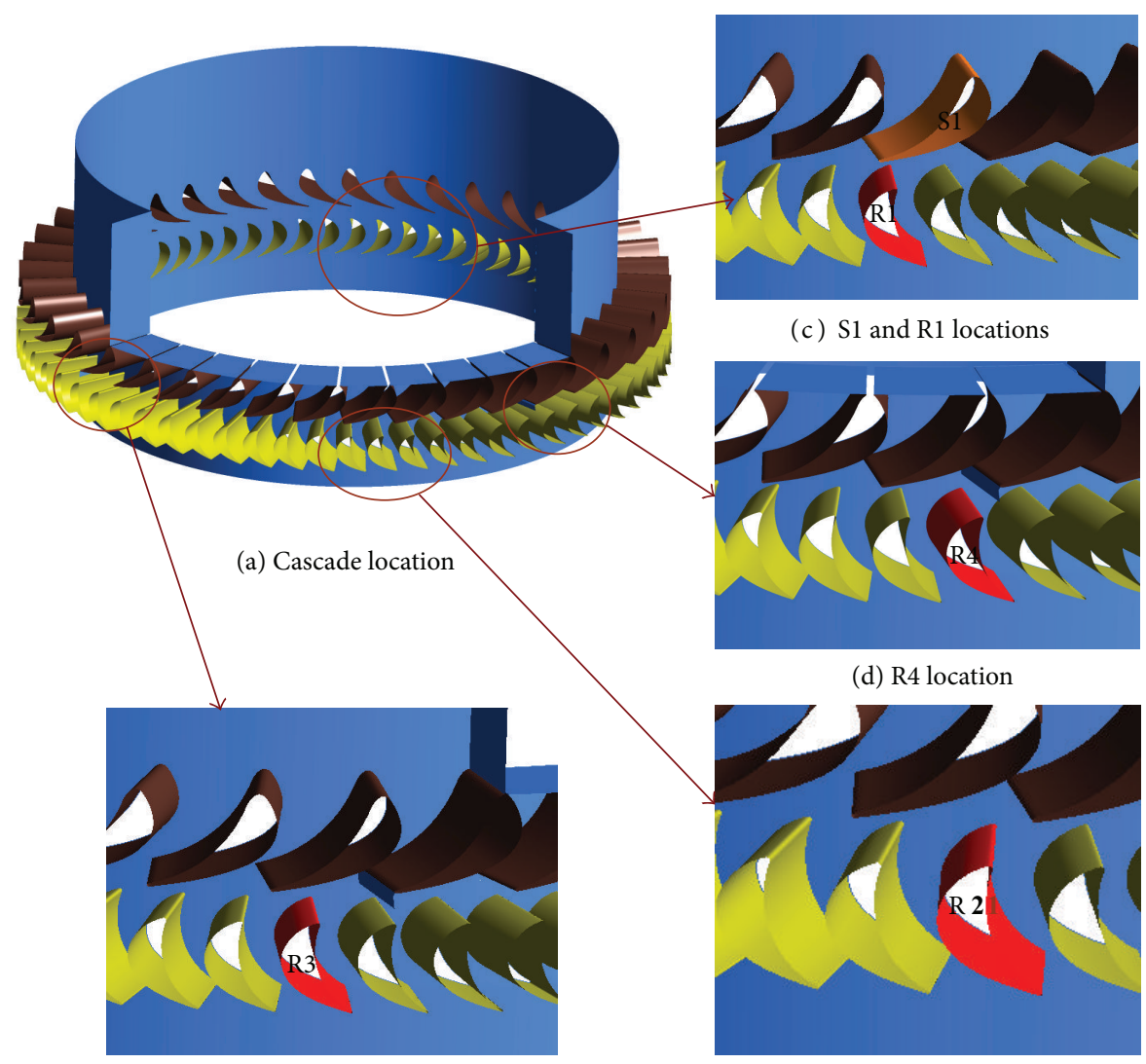

(b) R3 location

(e) R2 location

FIGURE 12: Location of blades.

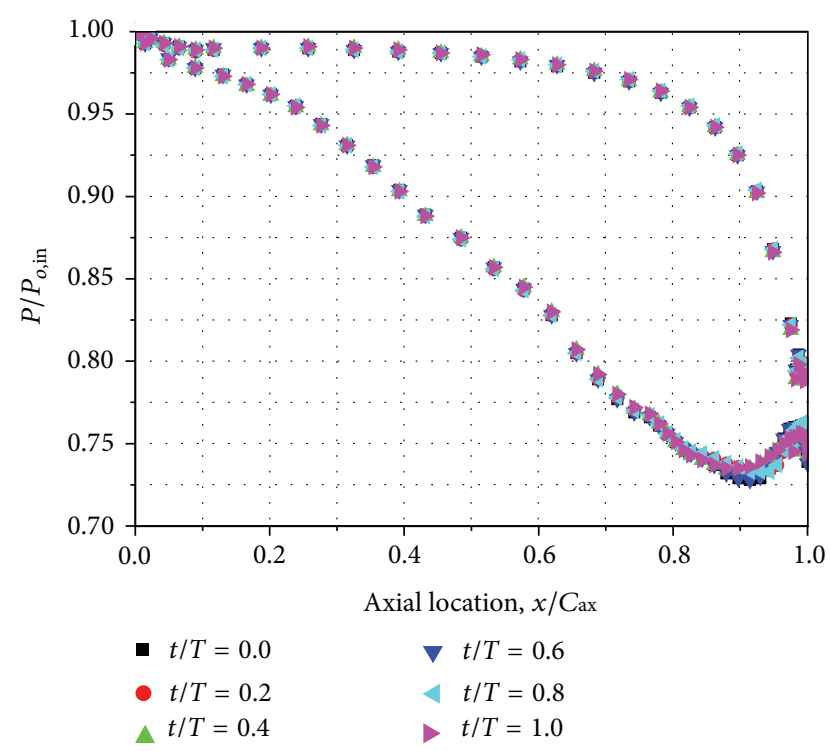

Figure 13: Static pressure distribution of S1 nozzle at 50\% blade height changes with time.

to increase with pressure surface enter into inlet section completely.

The static pressure distribution of 50 percentage blade height in one period is presented in Figure 17 for R4 rotor

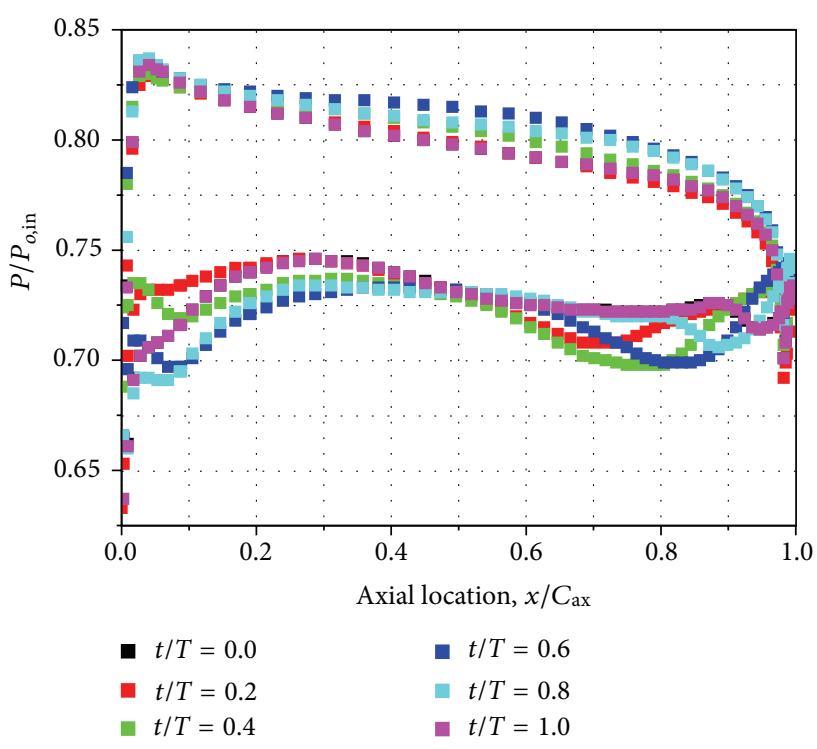

FIGURE 14: Static pressure distribution of R1 rotor at $50 \%$ blade height changes with time.

of transition section at the entrance to blocked section. It is presented that the maximum pressure of pressure surface of $\mathrm{R} 4$ rotor leading edge is lower than $\mathrm{R} 2$ rotor of inlet section. 


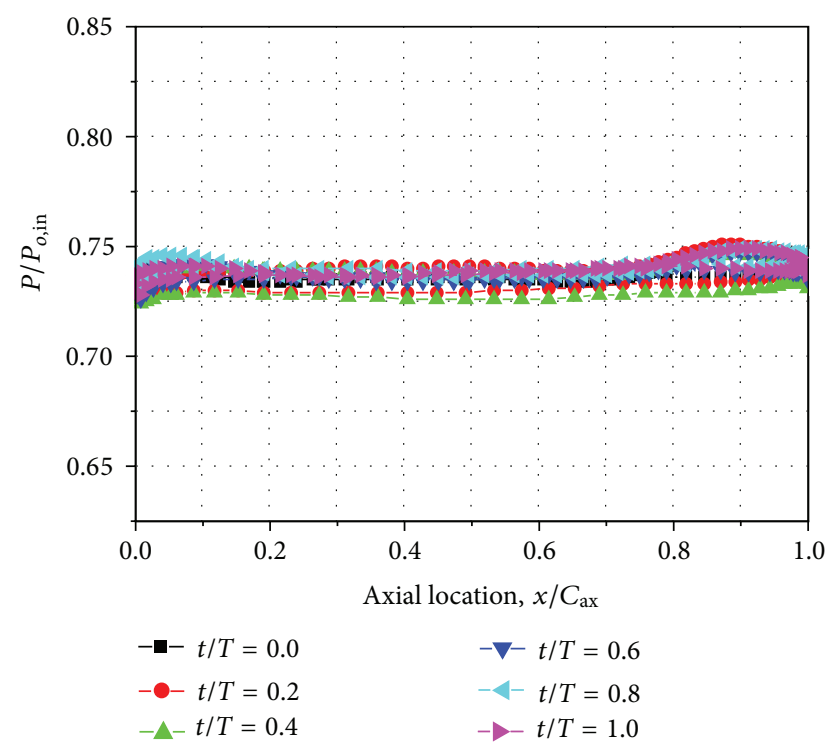

FIgURE 15: Static pressure distribution of R2 rotor at $50 \%$ blade height changes with time.

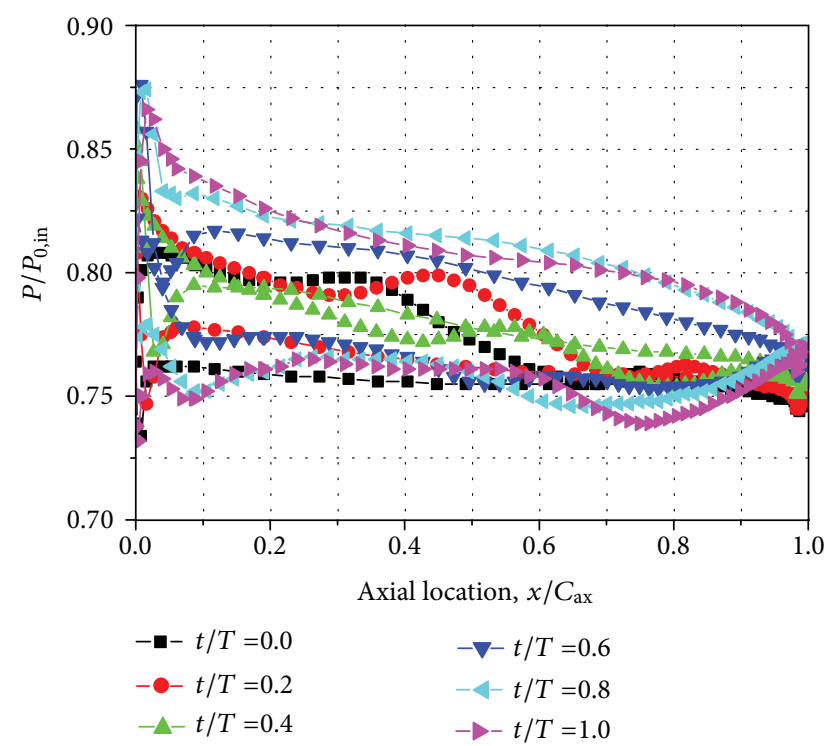

FIGURE 16: Static pressure distribution of R3 rotor at $50 \%$ blade height changes with time.

It is mainly because that part of air out of nozzle passage flows along the circumferential direction for the influence of blade rotation at the entrance to blocked section. And the losses caused. The pressure of pressure surface decreases gradually with time going on and the pressure distribution is close to $\mathrm{R} 1$ rotor pressure surface when $t / T$ is equal to 1.0. But the suction surface pressure presents the process of decreasing gradually and then rising again. The pressure of suction surface decreases gradually from $t / T$ equal to 0 to $t / T$ equal to 0.6 . The main reason is that the high speed flow is mixed with stagnant fluid in blocked section. And low pressure area appears. The flow of suction surface approaches

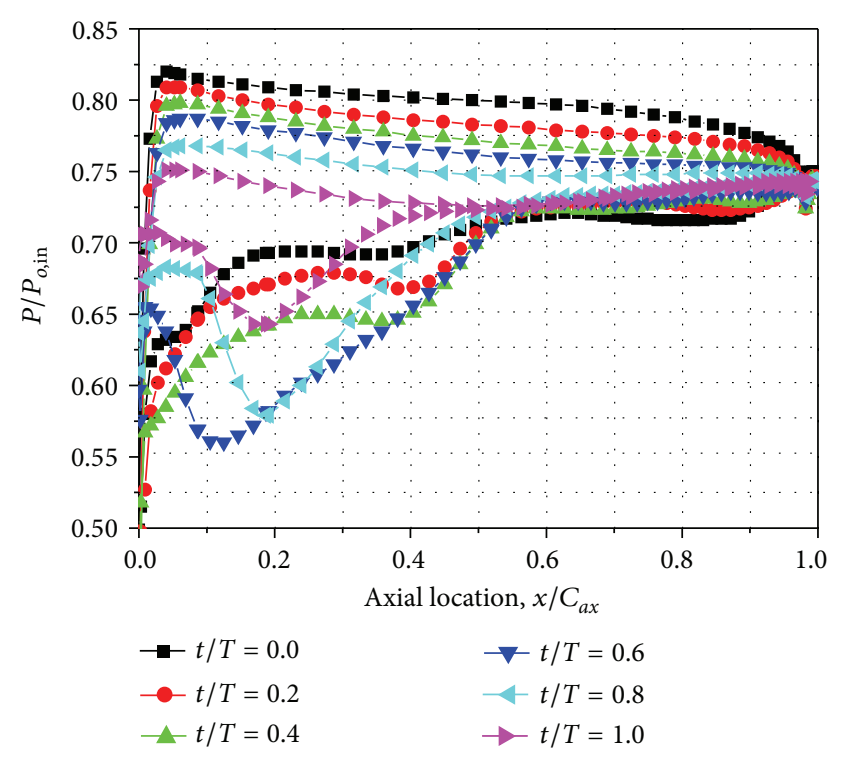

FIGURE 17: Static pressure distribution of R4 rotor at $50 \%$ blade height changes with time.

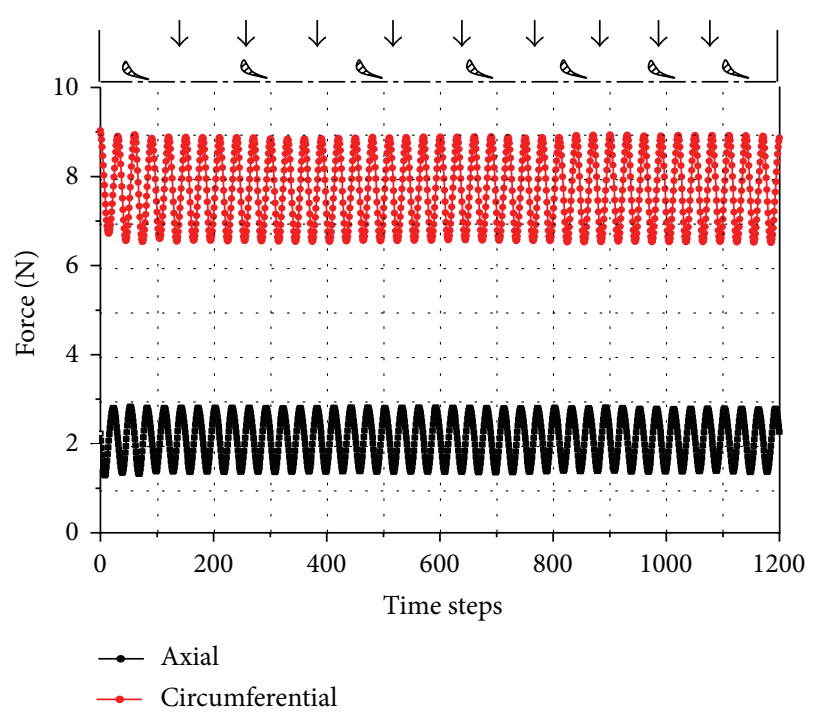

FIgURE 18: Axial and circumferential force distribution of rotor at different time steps in full admission.

to stable during the time from $t / T$ equal to 0.6 to $t / T$ equal to 1.0. The pressure increases.

The main reason of blade vibration failure is gas excitation force. Pulse graph of axial force and tangential force in one period at full admission is presented in Figure 18. And nozzle passage is shown at the top of Figure 18, which describes the relative location of rotor and nozzle at different time steps. Sine function period changes of axial force and tangential force are shown in the figure obviously, which is caused by upstream nozzle wake. The tangential force fluctuates near $8 \mathrm{~N}$ and the amplitude is $2 \mathrm{~N}$. The axial force fluctuates near $2 \mathrm{~N}$ and the amplitude is $2 \mathrm{~N}$. 


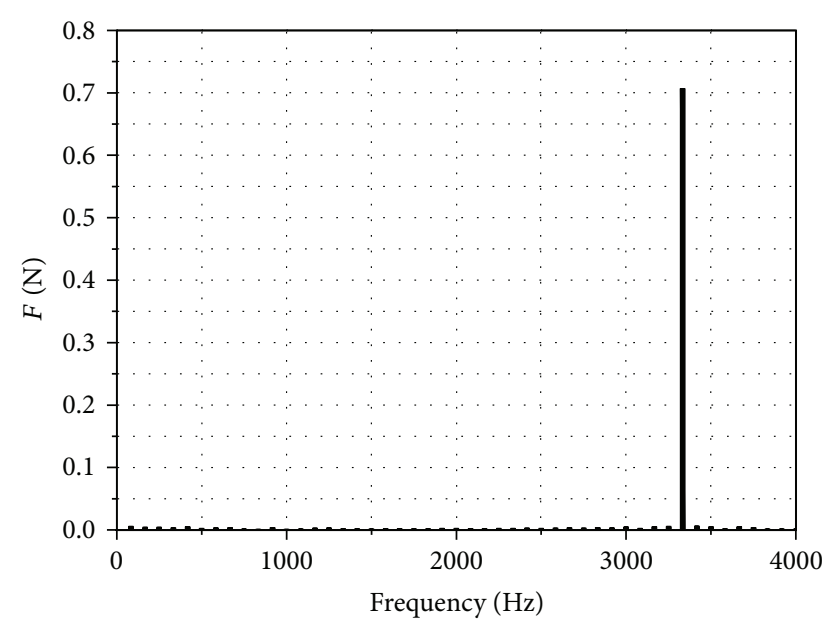

FIGURE 19: Frequency spectrum of rotor axial force in full admission.

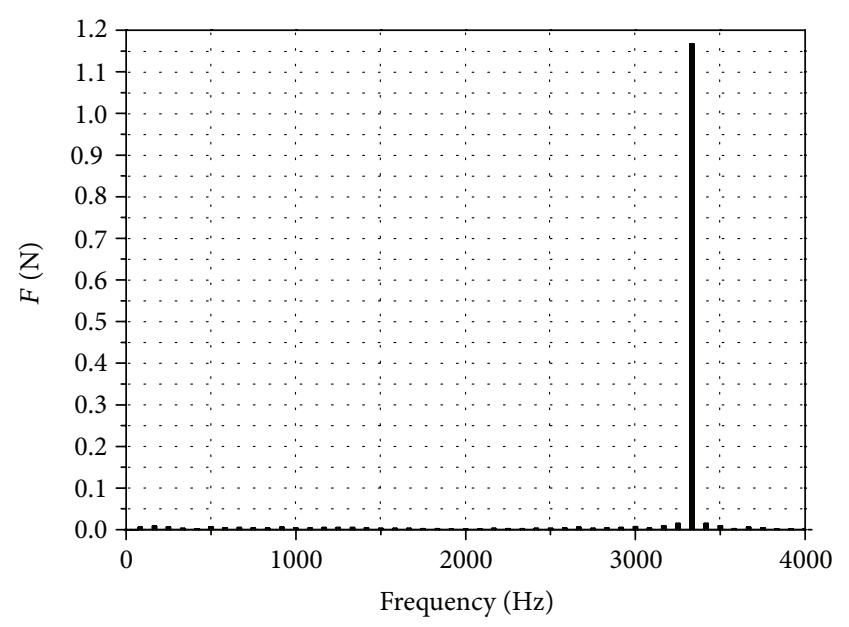

FIGURE 20: Frequency spectrum of rotor circumferential force in full admission.

The axial force and tangential force are analyzed by FFT (fast fourier transform). Relative frequency spectrograms are shown as Figures 19 and 20. The horizontal coordinate represents frequency of excitation force and the vertical coordinate represents excitation force amplitude. It is shown that the first-order high frequency of excitation force is $3333.33 \mathrm{~Hz}$ for tangential and axial force in Figures 19 and 20. It is resulted from the nonuniform of nozzle outlet flow. And the first-order high frequency of excitation force corresponds to theoretical analysis $(3333.33 \mathrm{~Hz})$.

According to the spectrum, the low and high frequency factor of excitation force at partial admission of 1.0 are shown as Table 5 .

The pulse graph of axial force and tangential force at partial admission of 0.75 in one period is shown in Figure 21. It is shown that the axial force decreases and tangential force increases obviously at $\mathrm{P}$ location. Due to $\mathrm{P}$ located at the upstream of blocked nozzle passage, the pressure surface is shocked by high speed flow and suction surface is full of stagnant fluid in blocked nozzle passage. The positive

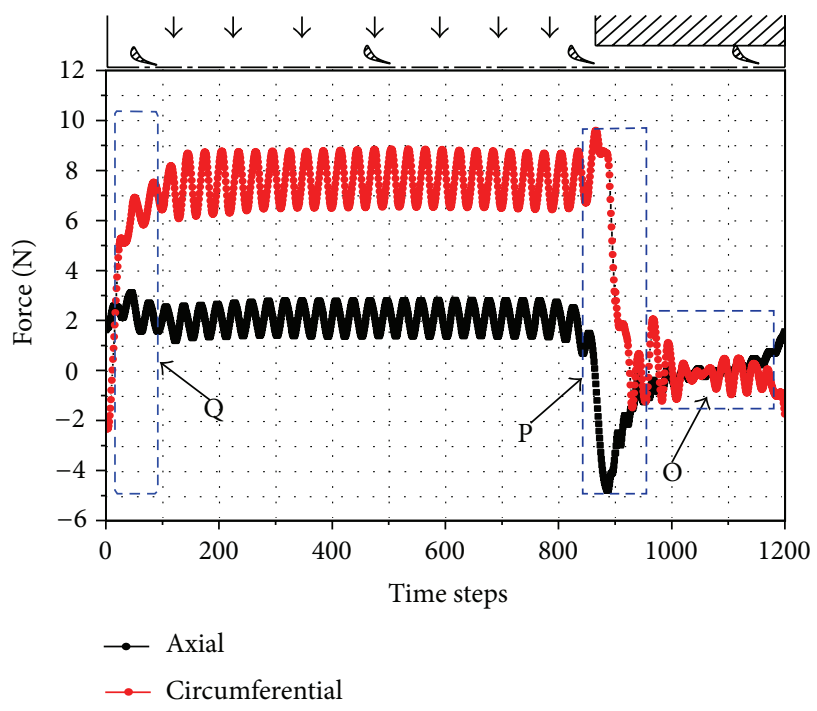

Figure 21: Axial and circumferential force distribution of rotor at different timestep in $75 \%$ admission.

extremum of tangential force arises and the force is $9.59 \mathrm{~N}$. The high speed flow mixed with stagnant fluid at the leading edge of suction surface. A low pressure area is formed, the negative extremum of axial force arises, and the force is $-4.80 \mathrm{~N}$. The axial and tangential forces of rotor drop to zero at the position of $\mathrm{O}$ suddenly, which is shown in Figure 21, because the flow passages are full of stagnant fluid at blocked section. The location $Q$ is at the entrance to blocked section. The suction surface passage influenced by incoming flow firstly, but pressure surface exists stagnant fluid so that the negative extreme value of tangential force arises. The negative extreme tangential force is $-2.34 \mathrm{~N}$, and the positive extreme axial force is $3.11 \mathrm{~N}$, shocked by high speed flow. The axial and tangential force of most part except for $\mathrm{P}, \mathrm{O}, \mathrm{Q}$ position is mainly effected by upstream nozzle wake, and it present the sine function periodic change. The tangential force distribution at the inlet section is like the full admission which the force fluctuates near $8 \mathrm{~N}$ with $2 \mathrm{~N}$ amplitude sinusoidal oscillation.

The axial force and tangential force are analyzed by FFT (Fast Fourier Transform). Relative frequency spectrograms are shown as Figures 22 and 23. It is shown the first-order low frequency excitation frequency of axial and tangential force are $83.33 \mathrm{~Hz}$, and another low frequency excitation frequency are integer multiple of $83.33 \mathrm{~Hz}$. The low frequency excitation force results from partial admission structure. It is shown directly that the high excitation frequency is $3333.33 \mathrm{~Hz}$, which results from nonuniform outlet flow of nozzle. The results correspond to the theoretical value $(3333.33 \mathrm{~Hz}$ for high frequency and $83.33 \mathrm{~Hz}$ for low frequency).

All kinds of values of axial and tangential force at partial admission of 0.75 are shown in Table 6 . The classical partial admission rectangular wave excitation force and local fine vibration force obtained from three-dimensional analysis are investigated in Table. It is shown that the ratio of local maximum excitation force and classical excitation force of 
TABLE 5: Excitation force factor.

\begin{tabular}{llcc}
\hline Excitation force direction & Excitation force parameters & First order & Second order \\
\hline Axial direction & High frequency excitation force factor & 0.336 & 0.014 \\
Tangential direction & High frequency excitation force factor & 0.151 & 0.007 \\
\hline
\end{tabular}

TABLE 6: Axial and circumferential force in 75\% admission.

\begin{tabular}{|c|c|c|c|}
\hline Excitation force & Parameters & Axial force & Tangential force \\
\hline \multirow{3}{*}{ Classical partial admission rectangular wave excitation force } & Maximum of inlet section/ $N$ & 2.79 & 8.86 \\
\hline & Minimum of inlet section/ $N$ & 1.38 & 6.52 \\
\hline & Average/ $N$ & 2.10 & 7.66 \\
\hline \multirow{4}{*}{ Partial admission local vibration force } & Maximum $/ N$ & 3.11 & 9.60 \\
\hline & Minimum $/ N$ & -4.80 & -2.34 \\
\hline & Maximum varied amplitude at $\mathrm{P}$ location $/ N$ & 7.31 & 11.10 \\
\hline & Maximum varied amplitude at Q location/ $N$ & 2.89 & 11.03 \\
\hline \multicolumn{2}{|c|}{ The ratio of local maximum excitation force and classical excitation force } & 3.48 & 1.45 \\
\hline
\end{tabular}

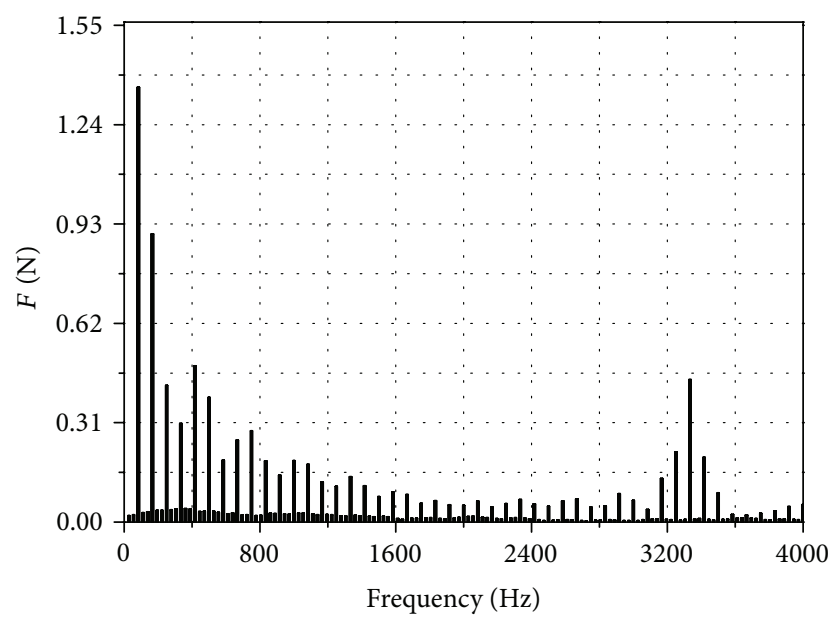

FIGURE 22: Frequency spectrum of rotor axial force in $75 \%$ admission.

axial force comes up to 3.48, and tangential force comes up to 1.45. The design of partial admission air turbine is something we need to fully pay attention to.

The low and high frequency excitation force factor at partial admission of 0.75 are shown in Table 7 according frequency spectrum.

\section{Summary and Conclusions}

Unsteady numerical analyses of small air turbine at four different partial admissions are carried out by using CFD technique. The results are as follows.

(1) Unsteady computation results present that timeaverage unsteady isentropic efficiency is lower than steady isentropic efficiency. The internal flow in turbine is more unsteady and the unsteady isentropic efficiency fluctuation increases with partial admission decreasing. The unsteady characteristics are more

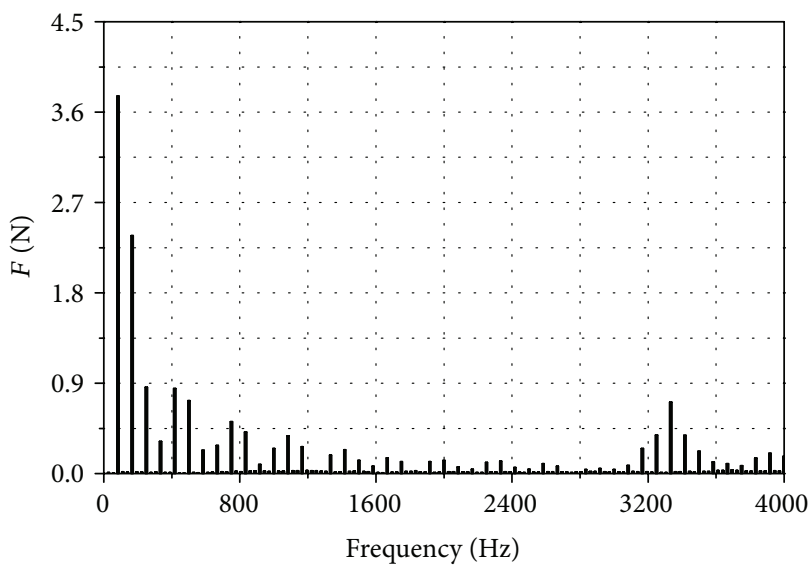

FIGURE 23: Frequency spectrum of rotor circumferential force in $75 \%$ admission.

obvious. The difference between maximum and minimum value of unsteady instantaneous isentropic efficiency is $1.834 \%$ at the partial admission of 0.25 , but the difference of unsteady instantaneous isentropic efficiency peak value is only $0.013 \%$ at full admission.

(2) The frequency analysis of axial force and tangential force of air turbine rotor at partial admission of 1.0 and 0.75 is conducted in this paper. The pulse spectrum of axial force and tangential force at different cases are obtained. When the partial admission is 1.0, sine function period changes of tangential force fluctuate near $8 \mathrm{~N}$, and the amplitude is $2 \mathrm{~N}$. The axial force fluctuates near $2 \mathrm{~N}$, and the amplitude is $2 \mathrm{~N}$. When the partial admission is 0.75 , the fluctuation curves of tangential and axial force at inlet section are the same as the partial admission of 1.0. The axial force and tangential force of rotor at blocked section fluctuate near $0 \mathrm{~N}$. The tangential force reaches maximum value and axial force reaches minimum value when the rotor is at the entrance to blocked section. And 
TABLE 7: Excitation force factor.

\begin{tabular}{llcc}
\hline Excitation force direction & Excitation force parameters & First order & Second order \\
\hline \multirow{2}{*}{ Axial direction } & Low frequency force factor & 0.645 & 0.429 \\
& High frequency force factor & 0.211 & 0.009 \\
\hline \multirow{2}{*}{ Tangential direction } & Low frequency force factor & 0.496 & 0.310 \\
& High frequency force factor & 0.093 & 0.004 \\
\hline
\end{tabular}

the tangential force reaches minimum value and axial force reaches maximum value when the rotor is at the entrance to inlet section.

(3) Low frequency, first-order, and second-order of high frequency excitation force factor are obtained by FFT analysis. The first-order of high frequency exciting factor of axial force is 0.336 and the first-order of high frequency exciting factor of tangential force is 0.151 when the partial admission is 1.0. The firstorder of low frequency exciting factor and high frequency exciting factor of axial force are 0.645, 0.211 , respectively, at partial admission of 0.75 . The first-order of low frequency exciting factor and high frequency exciting factor of tangential force are 0.496 , 0.093 , respectively. It is shown that the excitation force caused by partial admission is greater than the excitation force caused by nozzle wake, which is something we need to pay more attention to in engineering design.

\section{Conflict of Interests}

The authors declare that there is no conflict of interests regarding the publication of this paper.

\section{References}

[1] V. V. Pryakhin and A. Z. Pavlovskii, "Investigation of the influence of clearances in the flow section of a partial admission supersonic turbine stage," Thermal Engineering, vol. 17, no. 4, pp. 129-132, 1970.

[2] G. R. Wakeley and I. Potts, "Unsteady flow phenomena in partially-admitted steam turbine control stages, latest advances in the aerodynamics of turbomachinery with special emphasis on unsteady flows," in IMechE Seminar Publication, p. 21, 1996.

[3] L. He, "Computation of unsteady flow through steam turbine blade rows at partial admission," Proceedings of the Institution of Mechanical Engineers, Part A: Journal of Power and Energy, vol. 211, no. 3, pp. 197-205, 1997.

[4] P. Lampart, M. Szymaniak, and R. Rzadkowski, "Unsteady load of partial admission control stage rotor of a large power steam turbine," in Proceedings of the ASME Turbo Expo, pp. 237-246, ASME, Vienna, Austria, June 2004.

[5] N. Sakai, T. Harada, and Y. Imai, "Application of CFD to partial admission stages of steam turbine," in Proceedings of the ASME Power Conference, pp. 603-608, ASME, Chicago, Ill, USA, April 2005.

[6] S.-Y. Cho, C.-H. Cho, and C. Kim, "Effect of solidities and nozzle flow angles on a partially admitted small axial-type turbine," International Journal of Turbo \& Jet Engines, vol. 25, no. 2, pp. 111-120, 2008.
[7] Y. Li, Q. Zheng, and L. Sun, "The effect of partial admission on multistage radial inflow industrial steam turbine," in ASME Turbo Expo, pp. 623-629, June 2009, ASME paper.GT200959713.

[8] S.-Y. Cho, C.-H. Cho, K.-Y. Ahn, and Y.-C. Kim, "Forces and surface pressure on a blade moving in front of the admission region," Journal of Fluids Engineering, vol. 132, no. 12, Article ID 121101, 2010.

[9] N. B. Hushmandi, J. E. Fridh, and T. H. Fransson, "Unsteady forces of rotor blades in full and partial admission turbines," Journal of Turbomachinery, vol. 133, no. 4, Article ID 041017, 2011.

[10] P. Lampart, M. Szymaniak, and L. Jederzejewski, "Unsteady rotor blade forces in two types of turbine control stage," Advances in Vibration Engineering, vol. 11, no. 2, pp. 183-191, 2012.

[11] P. Newton, C. Copeland, R. Martinez-Botas, and M. Seiler, "An audit of aerodynamic loss in a double entry turbine under full and partial admission," International Journal of Heat and Fluid Flow, vol. 33, no. 1, pp. 70-80, 2012.

[12] J. Fridh, B. Laumert, and T. Fransson, "Forced response in axial turbines under the influence of partial admission," Journal of Turbomachinery, vol. 135, no. 4, Article ID 041014, 9 pages, 2013.

[13] V. Yakhot and S. A. Orszag, "Renormalization group analysis of turbulence. I. Basic theory," Journal of Scientific Computing, vol. 1, no. 1, pp. 3-51, 1986.

[14] A. Hajilouy-Benisi, M. Rad, and M. R. Shahhosseini, "Flow and performance characteristics of twin-entry radial turbine under full and extreme partial admission conditions," Archive of Applied Mechanics, vol. 79, no. 12, pp. 1127-1143, 2009.

[15] T. J. Barth and D. C. Jesperson, "The design and application of upwind schemes on unstructured meshes," in Proceedings of the AIAA 27th Aerospace Sciences Meeting, Reno, Nev, USA, 1989, AIAA-89-0366.

[16] A. Jamson, "Time dependent calculation using multigrid with applications to unsteady flows past airfoils and wings," in Proceedings of the 10th AIAA Computational Fluid Dynamics Conference, p. 1596, AIAA, Reston, Nev, USA, 1991. 


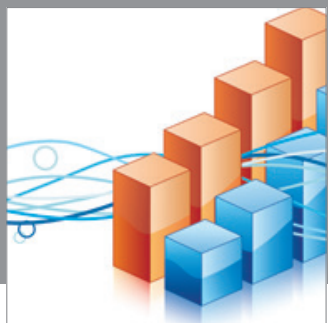

Advances in

Operations Research

mansans

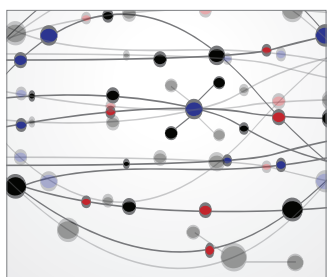

The Scientific World Journal
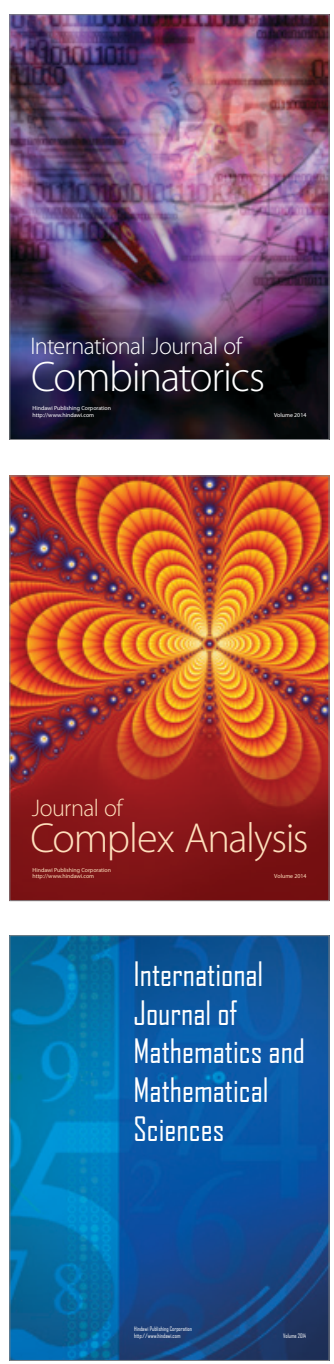
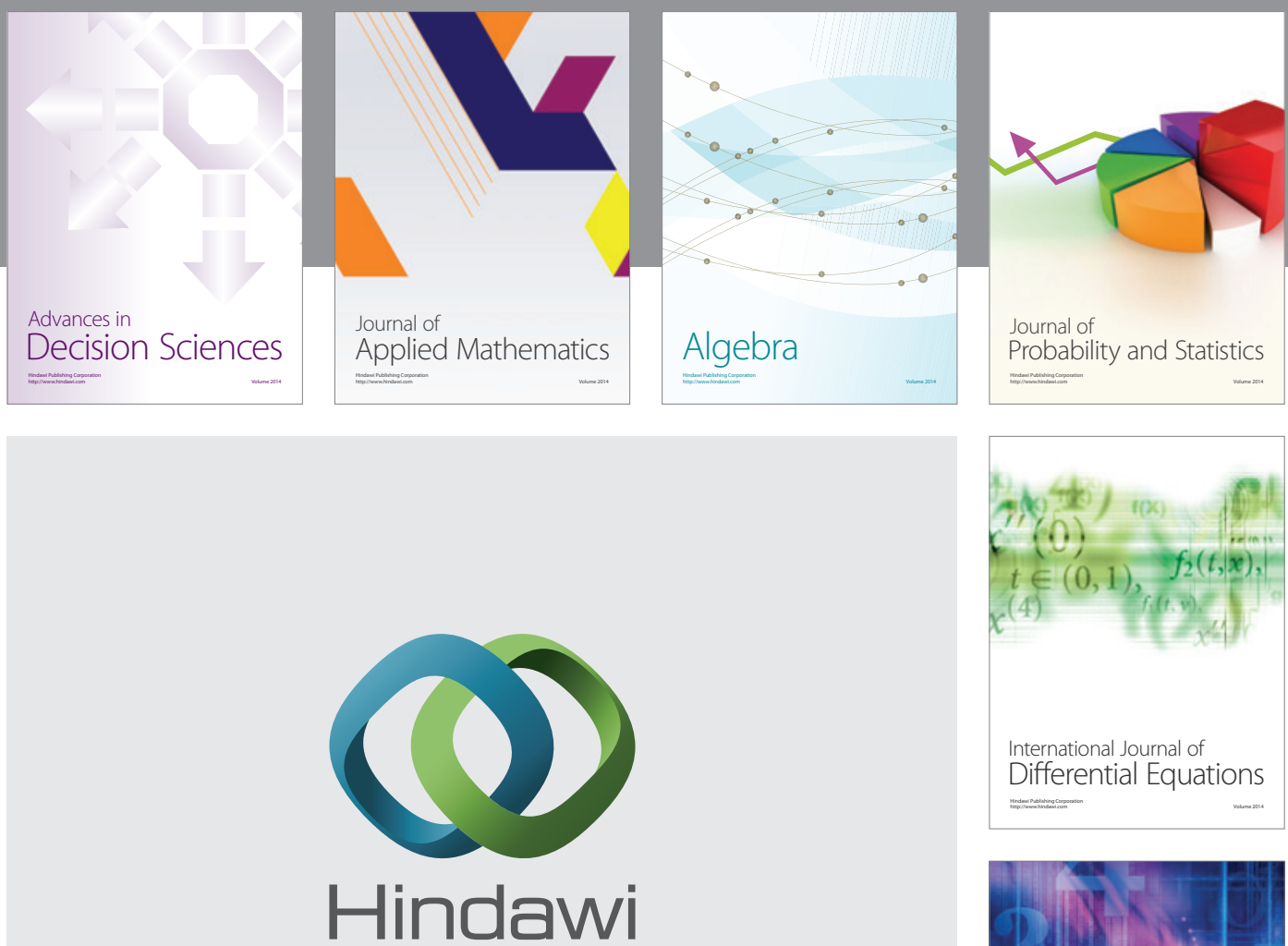

Submit your manuscripts at http://www.hindawi.com
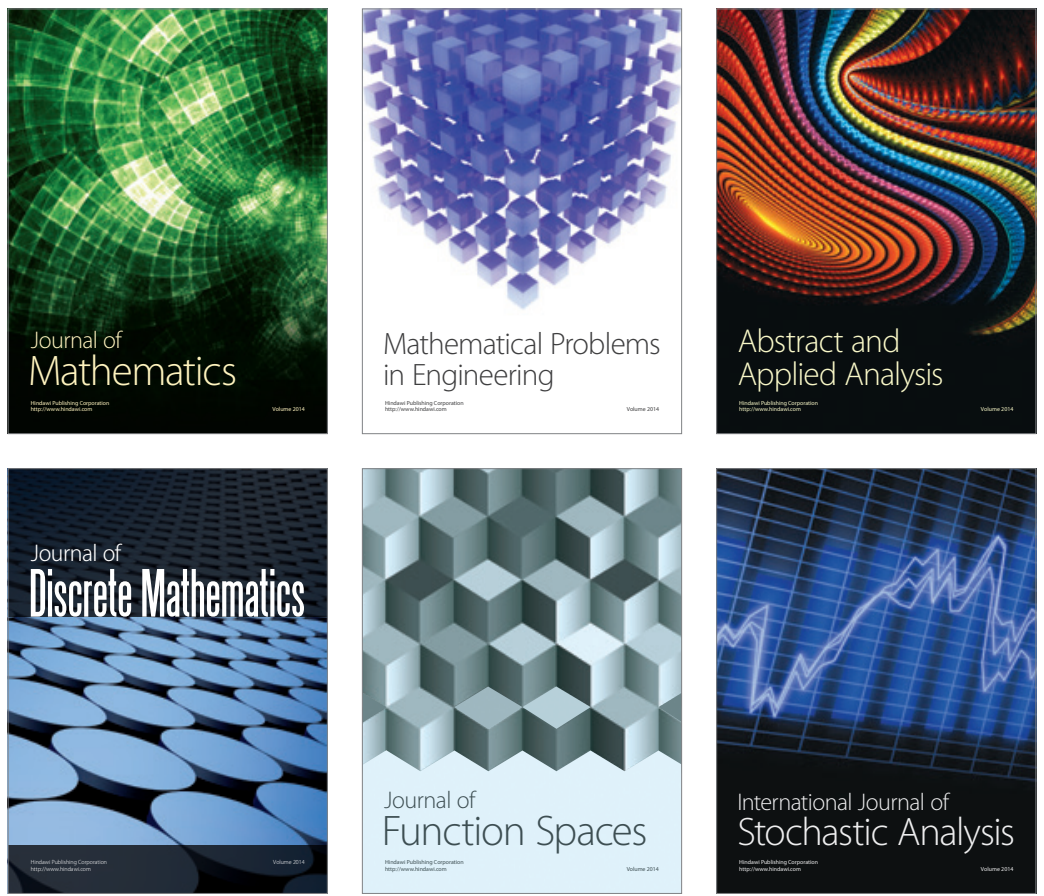

Journal of

Function Spaces

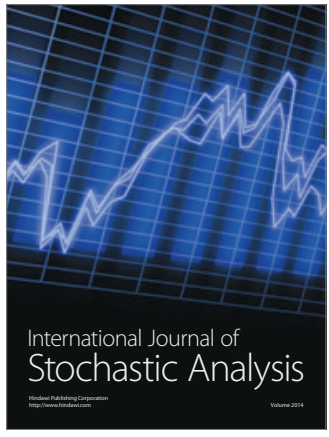

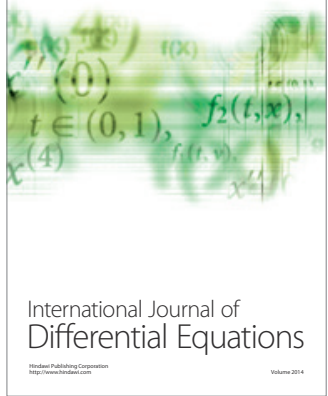
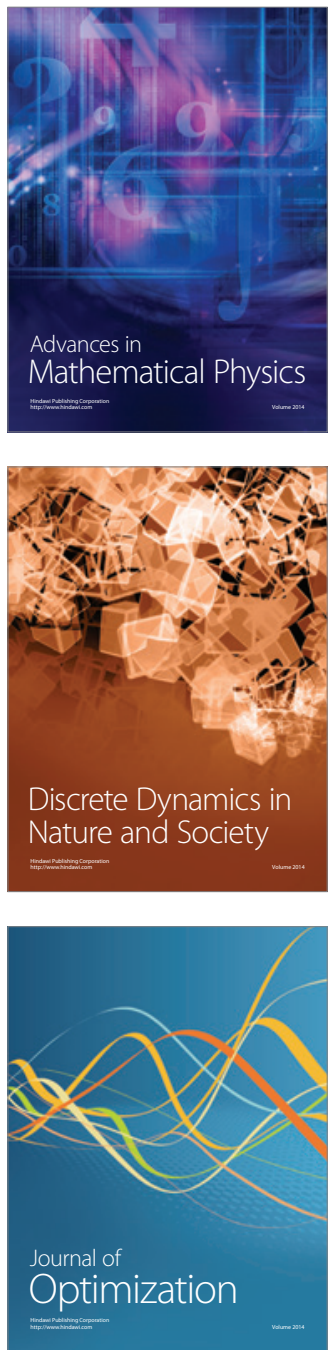